\title{
Molecular and Genetic Pathogenesis of Lung Cancer: Differences Between Small-Cell and Non-Small-Cell Carcinomas
}

\author{
Hitoshi Kitamura ${ }^{*}$, Takuya Yazawa $^{1}$, Koji Okudela ${ }^{1}$, Hiroaki Shimoyamada ${ }^{1}$ and Hanako Sato ${ }^{1,2}$ \\ ${ }^{I}$ Department of Pathology, Yokohama City University Graduate School of Medicine, Yokohama, Japan \\ ${ }^{2}$ Department of Anatomy, St. Marianna University School of Medicine, Kawasaki, Japan
}

\begin{abstract}
Lung cancer is classified into small-cell carcinoma (SCLC) and non-small-cell carcinoma (NSCLC). The profile of molecular and genetic alterations considerably differs between SCLC and NSCLC, as well as among the subtypes of NSCLC. Tp53 is inactivated in nearly $50 \%$ of NSCLC, while its mutations with functional inactivation are greatly prevalent in SCLC (70-100\%). Rb gene alterations and protein loss are found in virtually all SCLC, but rarely in NSCLC. Instead, the $\mathrm{Rb}$ function is abrogated due to dysfunction of the upstream regulators of the $\mathrm{Rb}$ pathway. $\mathrm{Tp} 53$ alterations are later events in adenocarcinoma, while they occur early in squamous cell carcinoma carcinogenesis. Recent studies demonstrated activating mutations of the epidermal growth factor receptor (EGFR) gene play a significantly important role in adenocarcinoma carcinogenesis. Activation of PIK3 catalytic alpha gene was recently found in nearly half of squamous cell carcinoma cases. Smoking is associated strongly with alterations of Tp53, K-ras, and PIK3 catalytic alpha, but weakly with EGFR gene mutations. Taken together silencing alterations of both the $\mathrm{Rb}$ and $\mathrm{Tp} 53$ genes are most likely to be important and early events in the development of SCLC, whereas alterations of the EGFR signaling pathway play significant and important roles in NSCLC carcinogenesis. The biological behavior and phenotype of the respective types of lung cancer would be attributable to these molecular and genetic alterations, but also reflect the difference in the ability of their precursor cells. Identifying the airway stem cell(s) and elucidating the molecular mechanism of its maintenance and activation are required.
\end{abstract}

Keywords: Lung cancer, small-cell lung carcinoma, non-small-cell lung carcinoma, molecular and genetic mechanism, Tp53, $\mathrm{Rb}$, epidermal growth factor receptor signaling pathway.

\section{INTRODUCTION}

Lung cancer is one of the most common malignancies worldwide and a leading cause of cancer-related deaths. It is increasing year by year in almost all areas of the world, except for a slight decrease in certain countries [1]. Lung cancer consists of heterogeneous groups in terms of pathological features and is commonly classified into the following two major types, small-cell lung carcinoma (SCLC) and nonsmall-cell lung carcinoma (NSCLC). NSCLC also is a group of heterogeneous histological types, the majority of which are squamous cell carcinoma (SCC) and adenocarcinoma (ADC) with roughly similar frequencies $(30-40 \%$ each), and large cell carcinoma (LCC) with a lower frequency $(<10 \%)$. SCLC comprises nearly $20 \%$ of lung cancer. ADC and LCC are further subclassified into several categories, respectively. The classification of lung cancer is not only of academic interest but also of practical necessity, because the biological aggressiveness, responsiveness to therapeutic intervention and patients' prognosis are greatly different among the respective types [2].

Lung cancer originates from the airway epithelia of larger and smaller bronchi as well as of alveoli. While it is generally accepted that cancer cells are derived from

*Address correspondence to this author at the Department of Pathology, Yokohama City University Graduate School of Medicine, 3-9 Fukuura, Kanazawa-ku, Yokohama 236-0004, Japan; Tel: 81-45-787-2583; Fax: 8145-789-0588; E-mail: pathola@med.yokohama-cu.ac.jp progenitor or tissue stem cells, relatively little has been elucidated with regard to the identification of airway stem cell(s) and the molecular mechanisms underlying their selfrenewal and differentiation abilities [3], in contrast to other epithelial tissues such as the intestine, mammary gland, and skin [4]. The heterogeneity of lung cancer likely reflects differences in the site of origin (proximal versus peripheral), and, more importantly, in the type of cell of origin, i.e., progenitor tissue stem cell. Cancer stem cell theory has proposed that a tumor cell subpopulation possessing selfrenewal capacity which forms only a small fraction of tumor tissue is central in sustaining neoplastic lesions and is a potentially crucial target of cancer therapy [5]. Cancer stem cell is possibly produced by multistep dedifferentiation of specialized epithelial cells through progressive accumulation of genetic aberrations [6].

The diversity of etiologic factors and target genes, the types of genetic insults, and the ensuing effects, activation or inactivation, on the genes involved, would also be responsible for the heterogeneity of lung cancer. In fact, tobacco smoke, containing more than 60 carcinogens, is generally accepted as the most important cause of almost all types of lung cancer, among which the genetic and molecular mechanisms of carcinogenesis differ considerably. The ensuing genetic alteration and epigenetic changes as well, could lead to dysfunction of molecular signal transduction pathways, which relate directly or indirectly to proliferation, differentiation, and death of the cell. 
Recent advances in biomedical technologies have significantly disclosed the mechanisms behind the pathogenesis of malignant neoplasia at the molecular and genetic levels. In brief, a malignant neoplasia originates from a single somatic cell (monoclonal) and progresses. The neoplastic cells eventually show an autonomous proliferative capability, a reduced sensitivity to growth inhibitory signals, evasion of programmed cell death such as apoptosis, unlimited replication, angiogenic activity, and invasive and metastatic capabilities, all of which are brought about through alterations of related genetic factors [7]. When established, clinically manifested, cancers are examined, neoplastic cells including lung cancer cells unexceptionally show alterations in several genes, most likely reflecting an accumulation of genetic alterations which occurred during the development and progression of the neoplasia [8]. Cancer cells are prone to undergo genetic alterations during replication compared to normal cells, a phenomenon termed genetic instability [9]. Owing to this genetic instability, gene alterations occur more frequently, at random, in cancer cells than in normal cells, resulting by chance in the production of progeny cells given with more advantageous growth activity than not only normal cells but also other cancer cells. Such cells exhibit greater population expansion and finally occupy most or even all of the neoplastic tissue. This process is termed subclonal evolution and represents the multistep carcinogenesis seen in many types of cancers including lung cancer. Subclonal evolution has been considered to occur stochastically under a variety of selective pressures. Genetic instability may be per se an initial step in the carcinogenesis.

This review focuses primarily upon recent studies in the field of research into lung cancer, which have newly disclosed genetic and molecular mechanisms, and attempts to correlate them with the classically denoted phenotypic features of lung cancer. Some studies on progenitor cells or tissue stem cells of the airway epithelia are also briefly reviewed.

\section{GENETIC ALTERATIONS IN LUNG CANCER}

Lung cancers exhibit not only common but also type- specific molecular and genetic alterations [2, 8]. Welldocumented genetic and molecular alterations in lung cancer are listed in Table 1 (from the data described in Reference 2 and other studies).

\section{Genetic Alterations Frequent in All Major Histological Types of Lung Cancer}

Mutation in the tumor suppressor gene Tp53 is one of the most frequent alterations. Inactivating mutations (mostly missense mutations) of the Tp53 gene are found in approximately $50 \%$ of NSCLC and more than $70 \%$ of SCLC.

Activation of Tp53 is induced by DNA damage and/or carcinogenesis stresses through transcriptional activation of the gene and stability of the protein by phosphorylation that leads to cell cycle arrest and the repair of damaged DNA, and apoptosis of DNA-damaged cells through transcriptional activation of many related genes [10] (Fig. 1). The Tp53 network and its machinery are elaborate [10]. Tp53 function is repressed by a variety of factors, including alterations of the gene itself, and the binding of the oncogenic adenoviral protein E1B, human papilloma viral protein E6, and SV40large $\mathrm{T}$ antigen, as well as endogenous $\mathrm{Mdm} 2$ protein. An ensuing effect of Tp53 inactivation that is important in carcinogenesis is the evasion by neoplastic cells of apoptosis and cell cycle arrest.

While alterations of Tp53 gene occur in the advanced stages of lung ADC, it is an early event in the multistep carcinogenesis of bronchogenic SCC. During the developmental sequence from atypical adenomatous hyperplasia (AAH) to bronchioloalveolar carcinoma (BAC), Tp53 gene alterations significantly increase at the step of malignant conversion and emergence of invasive growth $[11,12]$. In contrast, in SCC, Tp53 gene alterations are detected as early as in squamous metaplasia and dysplasia during the developmental sequence [13].

We have no idea when alterations of the Tp53 gene occur during the carcinogenesis of SCLC since the putative precursor lesion of human SCLC is still unknown. However, it may be a very early event as suggested by findings in a mouse

Table 1. Representative Profile of Molecular and Genetic Alterations in Major Histological Types of Lung Cancer ${ }^{a}$

\begin{tabular}{|c|c|c|c|c|c|c|c|c|c|}
\hline $\begin{array}{c}\text { Histological } \\
\text { Type }\end{array}$ & $\begin{array}{c}\text { Tp53 } \\
\text { Inactivation* }\end{array}$ & $\begin{array}{c}\mathbf{R b} \\
\text { Inacti- } \\
\text { vation** }\end{array}$ & $\begin{array}{c}\text { E2F1 } \\
\text { Over- } \\
\text { expression }\end{array}$ & $\begin{array}{c}\text { K-Ras } \\
\text { Mutations }\end{array}$ & $\begin{array}{l}\text { EGFR Muta- } \\
\text { tions/ } \\
\text { Amplification }\end{array}$ & $\begin{array}{c}\text { PIK3CA } \\
\text { Mutations/ } \\
\text { Amplification }\end{array}$ & $\begin{array}{l}\text { c-Myc } \\
\text { Ampli- } \\
\text { fication }\end{array}$ & \begin{tabular}{|c|} 
Cyclin \\
D1 \\
Over- \\
exprssion
\end{tabular} & $\begin{array}{c}\text { p16/Ink4 } \\
\text { Inactivation*** }\end{array}$ \\
\hline SCLC & $>70 \%$ & $\sim 100 \%$ & $\sim 100 \%$ & $\sim 0 \%$ & $\sim 0 \%$ & & $\sim 30 \%$ & $\sim 0 \%$ & $\sim 0 \%$ \\
\hline SCC & $\sim 50 \%$ & $<15 \%$ & $\sim 20 \%$ & $\sim 0 \%$ & $(>85 \%)$ & $\sim 50 \%$ & & $\sim 50 \%$ & $\sim 80 \%$ \\
\hline (Dyslasia) & yes & (yes) & (yes) & $\sim 0 \%$ & (yes) & & & & (yes) \\
\hline $\mathrm{ADC}$ & $\sim 50 \%$ & $<15 \%$ & $\sim 10 \%$ & $10-30 \%$ & $40-60 \%$ & $\sim 10 \%$ & & $\sim 45 \%$ & $\sim 70 \%$ \\
\hline BAC & $\sim 30 \%$ & $\sim 0 \%$ & & $10-30 \%$ & $10-30 \%$ & & & & \\
\hline (AAH) & $\sim 0 \%$ & $\sim 0 \%$ & & $10-30 \%$ & $3-25 \%$ & & & & \\
\hline $\mathrm{LCC}^{\#}$ & $\sim 50 \%$ & $<15 \%$ & & & & & & & (yes) \\
\hline$\left(\mathrm{LCNEC}^{\$}\right)$ & $\sim 50 \%$ & $50-70 \%$ & $\sim 50 \%$ & $\sim 0 \%$ & & & & & \\
\hline
\end{tabular}

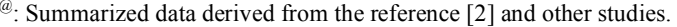

SCLC: small-cell lung carcinoma, SCC: Squamous cell carcinoma, ADC: Adenocarcinoma (including advanced BAC in some studies), BAC: Bronchioloalveolar carcinoma, AAH: Atypical adenomatous hyperplasia, LCC: Large cell carcinoma, LCNEC: Large cell neuroendocrine carcinoma, yes: Some studies reported positive results, but the number of cases studied were too small to register exact frequencies; *: Mutations/deletions and loss of function, **: mutations/deletions and loss of protein, ***: Mainly promoter hypermethylation, ( ): Immunohistochemistry results, ${ }^{\#}$ : Similar to other NSCLC, ${ }^{\$}$ : Overall similar to SCLC or intermediate between NSCLC and SCLC. 


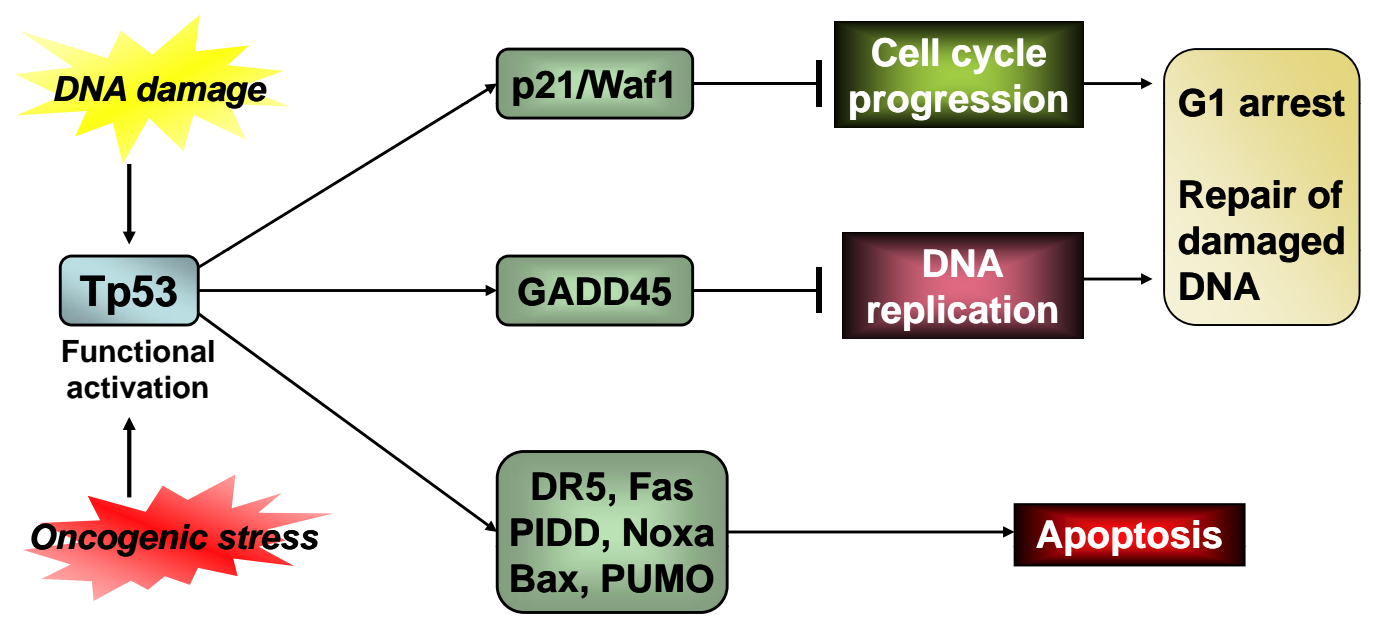

Fig. (1). Simplified and classical schema illustrating the role of Tp53 protein in either repair of damaged DNA of the cell or elimination of cells with severely damaged DNA through apoptosis in response to DNA injuries and in some instance to oncogenic stress.

SCLC model [14]. In addition, it is strongly suggested that Tp53 gene alterations are essential to the occurrence of SCLC based on results obtained from human cases [8] as well as the mouse model [14].

The second most common alteration is inactivation of the tumor suppressor retinoblastoma $(\mathrm{Rb})$. The mechanism of inactivation of the $\mathrm{Rb}$-controlling pathway is either a loss or a constitutional alteration of $\mathrm{Rb}$ protein due to genetic abnormalities, or the protein inactivation by hyperphosphorylation due to silencing of the p16/Ink4 gene through a genetic (homozygous deletions/mutations) or epigenetic (promoter hypermethylation) mechanism, and overexpression of cyclin D1 due to gene amplification [15, 16] (Fig. 2). It is of great significance that loss of $\mathrm{Rb}$ protein mostly owing to mutations and/or deletions of the $\mathrm{Rb}$ gene are detectable in almost all SCLC, along with a normal p16/Ink4 gene and cyclin D1 protein expression. In contrast, alterations of the $\mathrm{Rb}$ gene are found in only about $15 \%$ of NSCLC, while silencing of the p16/Ink4 gene through homozygous deletions and/or mutations and promoter hypermethylation is detected in up to $80 \%$ of NSCLC, and overexpression of cyclin D1 protein due to gene amplification or by other mechanisms in nearly $50 \%[8,15-18]$.

$\mathrm{Rb}$ protein is one of the regulators of the critical G1 to Sphase cell cycle transition $[19,20]$. Rb protein is functionally inactivated through phosphorylation by cyclin dependent kinase (Cdk) 4/6/cyclin D1, Cdk2/cyclin E, and Cdk2/cyclin A, whose activities are controlled and repressed by the members of the Kip and Ink4 families [15, 16]. Inactivated $\mathrm{Rb}$ protein releases E2Fs that are indispensable to the transcriptional activation of a number of genes whose products are necessary for cell cycle progression, cell differentiation, and cell survival (Fig. 2). In the vast majority of SCLC, Rb activity would be abraded nearly completely due to either the loss or constitutional alterations of $\mathrm{Rb}$ protein due to $\mathrm{Rb}$ gene alterations (Fig. 2A). In contrast, only a small fraction of NSCLC harbor mutated or deleted Rb genes, thus, dysfunction of the $\mathrm{Rb}$ pathway in NSCLC could ensue from inactivation of multiple upstream components including the Kip and Ink4 families as well as from overexpression of cyclin D1 (Fig. 2B). Accordingly, the repression of Rb function, even if it does occur, would not be complete because putative compensatory functions potentially work through other preserved collateral pathways. Some studies indicate that $\mathrm{Rb}$ protein also induces apoptosis $[19,20]$ and its inactivation would also be important in this regard for carcinogenesis (Fig. 2).

Loss of heterozygosity $(\mathrm{LOH})$ in $3 p$ is the third most common genetic alteration detected in almost all types of lung cancer. This region contains several putative tumor suppressor genes, but the contribution of LOH at $3 p$ to lung cancer has yet to be clarified [8].

\section{Genetic Alterations Specific for Respective Histological Types of Lung Cancer}

\section{Small-Cell Lung Carcinoma (SCLC)}

SCLC is the most aggressive lung cancer and almost fatal despite a good initial response to chemo-radiation therapy [21]. The neoplastic cells exhibit neuroendocrine (NE) features as evidenced by the expression of a variety of NE cell markers. In addition, interestingly, they express thyroid transcription factor 1 (TTF1) that is very specific to the peripheral airway epithelia and the majority of lung ADC, particularly BAC, though neither the significance nor the mechanism of TTF1 expression in SCLC has been elucidated yet.

As mentioned above, inactivation of the Tp53 gene and $\mathrm{Rb}$ gene (missense mutations and $\mathrm{LOH}$ ) occurs in the vast majority of SCLC cases $[15,16,21]$. Other molecular alterations usually found in SCLC include E2Fs' overexpression $[22,23]$ and Myc family gene amplification [24, 25] that are responsible for an acceleration of cell replication. On the other hand, the apoptotic signal pathways are also disrupted in most SCLC through not only Tp53 gene inactivation but also dysfunction of E2Fs and Myc family members [25, 26]. EGFR protein overexpression and K-ras gene mutations are virtually absent in SCLC [21].

Meuwissen et al. [14] have developed an experimental model of SCLC in mice in which the Rb and Tp53 genes can be conditionally deleted in the airway epithelia. Mice having homozygous deletions of both the Tp53 and Rb genes developed a highly aggressive and widely metastatic neoplasia consisting of small cells with scanty cytoplasm, the features indistinguishable from those of human SCLC. It was con- 


\section{SCLC}

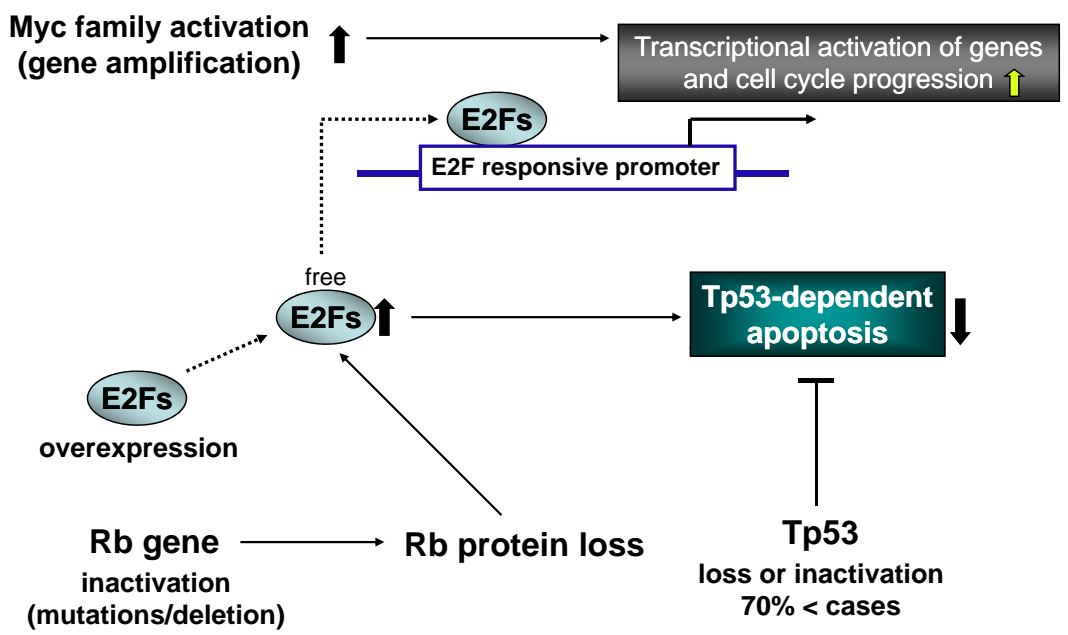

(B)

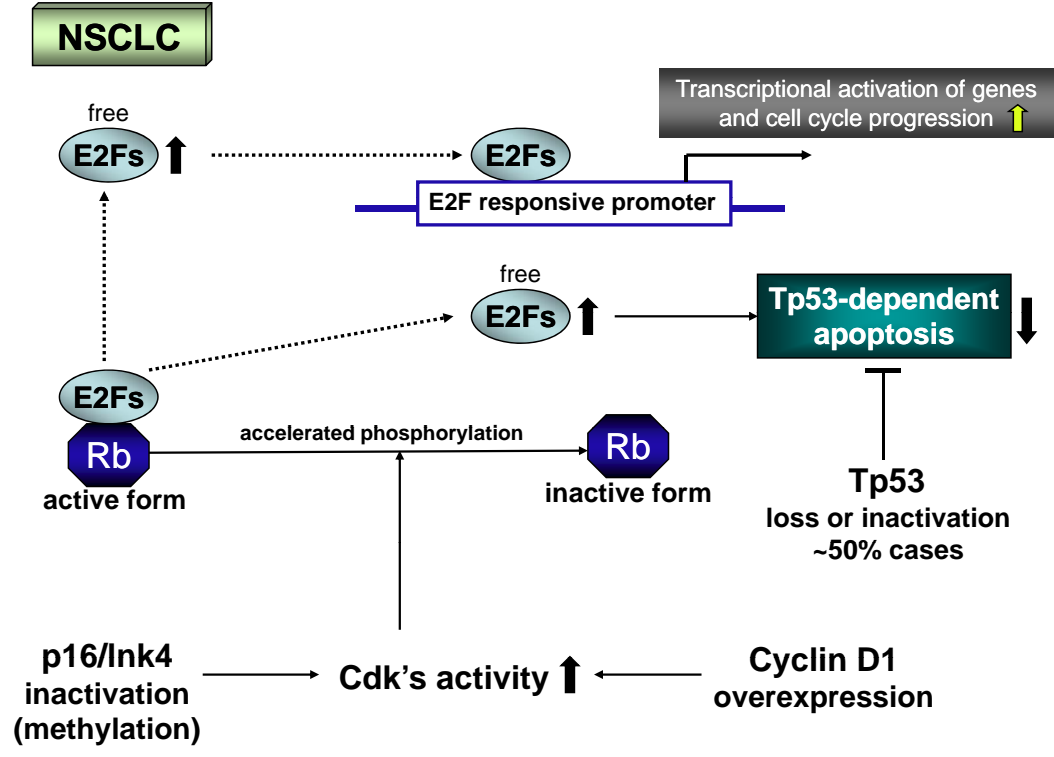

Fig. (2). The mechanisms of Rb function loss and its role in carcinogenesis of small-cell lung carcinoma (SCLC) (A) and non-small-cell lung carcinoma (NSCLC) (B). When hyperphosphorylated by the cyclin dependent kinases (Cdks), Rb protein is inactivated and releases E2Fs. The activities of Cdks are controlled by upstream factors such as p16/Ink4 and cyclin D1, and so on. Free E2Fs transactivate genes necessary for cell cycle progression and in certain instances mediate Tp53 dependent apoptosis. (A) In addition to an increase of free E2Fs due to Rb protein loss, overexpression of E2Fs is also frequent in SCLC. Furthermore, Myc family members are not uncommonly overexpressed through gene amplification. Tp53 dependent apoptosis mediated by free E2Fs is inhibited by loss of function of Tp53 in $>70 \%$ of cases, as well as by activation of anti-apoptotic pathway, such as Bcl-2 overexpression (not shown here). (B) In NSCLC, Rb function is inactivated by accelerated phosphorylation of constitutionally normal $\mathrm{Rb}$ protein through increased activity of cyclin dependent kinases (Cdks) that is brought about by p16/Ink4 inactivation, cyclin D1 overexpression, and other mechanisms (not shown here). Free E2Fs released from inactivated $\mathrm{Rb}$ protein mediate cell cycle progression. E2Fs-mediated Tp53 dependent apoptosis could be inhibited due to Tp53 inactivation in around $50 \%$ of NSCLC.

firmed that these cells differentiate toward the NE lineage by demonstrating the expression of NE markers, TTF1, and the mouse homolog of human achaete-scute complex homologlike 1 (MASH1). This neoplasia was termed mouse SCLC. In mice with homozygous $\mathrm{Tp} 53$ gene deletions and heterozygous $\mathrm{Rb}$ gene deletions SCLC also occurred, but the tumor incidence was lower, the time required for tumor development was longer, and the size of developed tumor was smaller than those seen in mice with homozygous deletions of both $\mathrm{Tp} 53$ and $\mathrm{Rb}$ genes. Genetic analysis of tumors in mice with homozygous Tp53 gene deletions and heterozygous $\mathrm{Rb}$ gene deletions demonstrated homozygous deletions of both $\mathrm{Tp} 53$ and $\mathrm{Rb}$ genes, the results implicating that the originally normal $\mathrm{Rb}$ gene on one allele was deleted during tumor development. From these results homozygous deletions of both $\mathrm{Tp} 53$ and $\mathrm{Rb}$ genes were supposed to be essential for the development of mouse SCLC. 
Hyperplastic and dysplastic lesions with high cell proliferation activity also were observed in the bronchial epithelia of this mouse model. Cells comprising these lesions expressed NE markers, TTF1 and MASH1, and were considered to be the precursor lesions of mouse SCLC. A microdissection study coupled with polymerase chain reaction demonstrated homozygous deletions of Tp53 and Rb genes in the cells comprising hyperplastic and dysplastic lesions. It was thus considered that homozygous deletions of both genes are not sufficient for the full development of mouse SCLC and additional genetic alterations are required. It is assumed that $\mathrm{Rb}$ gene deletions are essential for promoting the proliferation and retaining the differentiation of the cells committed toward the NE lineage. Evasion of apoptosis caused by Tp53 gene deletion is likely more important in the propagation of such altered preneoplastic cells. These observations are overall consistent with the results of genetic and molecular analyses of human SCLC.

Another study using a mouse model of conditional deletion of the $\mathrm{Rb}$ gene demonstrated that $\mathrm{Rb}$ controls the fate of airway epithelial cells [27]. In the embryonic stage, Rb deletion resulted in prominent proliferation of airway epithelial cells of non-characterized type. Natal and postnatal mice with $\mathrm{Rb}$ deletion exhibited a conspicuous increase of airway $\mathrm{NE}$ cells, perhaps due to induction into the NE cell lineage together with enhancement of cell proliferation. Non-NE airway cells such as Clara cells and type 2 cells appeared to normally develop. From these results, the author concluded that $\mathrm{Rb}$ has cell lineage-specific role that is essential for the regulation of $\mathrm{NE}$ cell fate.

Considering the results from these two experimental studies, it is supposed that Rb loss in SCSL has a role not only in NE lineage cell specification but also in enhancement of cell cycle progression preferentially of these cells (Fig. 3). Tp53 loss potentially functions in evasion of apoptosis, escape from cell cycle arrest, and induction of genetic instability.

\section{Squamous Cell Carcinoma (SCC)}

Overexpression of the epidermal growth factor receptor (EGFR) protein assessed by immunohistochemistry is more frequent in $\mathrm{SCC}(80 \%$ to $90 \%)$ than in other types of NSCLC [17]. A recent study showed that EGFR immunore- activity was correlated with EGFR tyrosine kinase domain mutations in lung cancer, but this trend was rather strong in ADC [28]. K-ras gene mutations are rare in SCC as in other NSCLC except ADC [13]. Okudela et al. [29] recently demonstrated activating mutations and amplification of the PIK3 catalytic, alpha (PIK3CA) gene in about $50 \%$ of lung SCC and stressed that the activation of downstream components in the EGFR signaling pathway is important for the development of lung SCC. They also noticed that PIK3CA gene activation and amplification were strongly associated with smoking. Tp53 gene inactivation also is frequent in SCC as in other types of NSCLC (approximately 50\%). While $\mathrm{Rb}$ gene mutations are rare, the upstream components of the $\mathrm{Rb}$ pathway are disrupted in SCC as in other NSCLC, either by overexpression of cyclin D1 protein (gene amplification or by other mechanisms) or through $\mathrm{p} 16 /$ Ink4 gene silencing due to genetic (homozygous deletions/mutations) or epigenetic (promoter methylation) mechanisms [17].

\section{Adenocarcinoma (ADC)}

While lung ADC is a group of heterogeneous histological subtypes, the majority of tumors occur in the lung periphery. Lung ADC is unique in having frequent mutations of the Kras gene, most of which are in codon 12 , in contrast to SCC and SCLC which hardly show any K-ras gene mutations. However, the frequency of K-ras gene mutations has been reported to be up to $30 \%$ in lung ADC. K-ras gene mutations are detectable in AAH lesions, a putative precursor of peripheral lung AC, particularly BAC [30]. As in other types of NSCLC, inactivation of the Tp53 gene is frequent (approximately $50 \%$ of cases) and is detectable preferentially in advanced lung ADC including those with the BAC pattern (advanced BAC) [30].

Recent studies demonstrated activating mutations of the EGFR gene in $40-50 \%$ of lung ADC and these cases showed no K-ras gene mutations. Thus, EGFR gene mutations and K-ras gene mutations are mutually exclusive in lung ADC [31-33] These investigators also detected EGFR gene mutations at a high frequency in AAH lesions without K-ras gene mutations and reported that the proportion of lesions with EGFR gene mutations increased with the progression of disease whereas the proportion of lesions with K-ras gene mutations was unchanged or even decreased. They concluded that

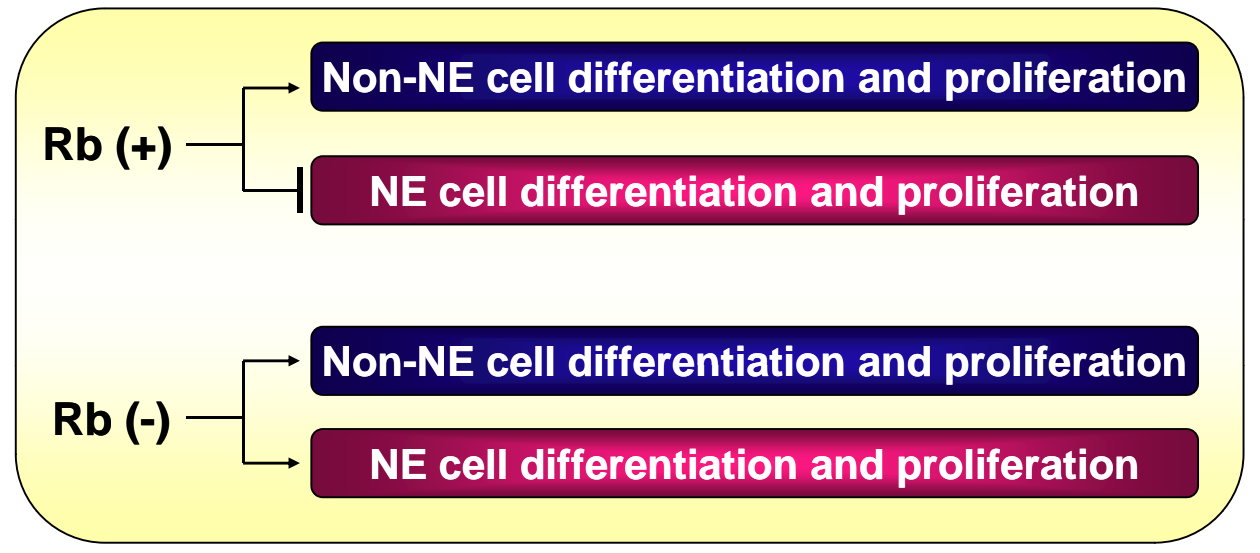

Fig. (3). The role of $\mathrm{Rb}$ in airway epithelial cell fate determination during development and pulmonary carcinogenesis. Non-neuroendocrine (non-NE) cell differentiation and proliferation are not affected by the presence or absence of Rb function. Rb regulates differentiation and proliferation of cells in the NE lineage, and Rb function loss enhances NE cell differentiation and proliferation, not only during development perhaps but also in SCLC carcinogenesis. 
EGFR gene mutations are more important for the development and progression of lung ADC than K-ras gene mutations. Okudela et al. detected PIK3CA gene mutations in $12 \%$ of lung ADC [29]. They augured that the activation of the EGFR signaling pathway, including activation of the downstream mediators, is essential for the development of SCC and ADC, though the main downstream pathway appears to differ between the two.

It has been assumed that the type 2 pneumocyte, Clara cell, and/or, precursor cell common to these two cell types is the cell of origin for peripheral lung $\mathrm{ADC}$, particularly for BAC [3].

Kim et al. [34] identified bronchioalveolar (tissue) stem cells coexpressing Clara cell specific antigen CCA and type 2 pneumocyte specific SP-C in the niche of the bronchioalveolar junction of the mouse lung. These cells actively proliferated to repair injured bronchial and alveolar epithelia. Isolated cells from this population were capable of proliferating in vitro and forming colonies composed of type 2 pneumocytes, type 1 pneumocytes and Clara cells. A single cell isolated from these colonies also exhibited the capability to propagate in vitro and to produce similar progeny cells as mentioned above. From these results, it is evident that the cells are capable of both self-renewal and pluripotent differentiation, being consistent with the definition of a stem cell. Furthermore, it is of interest that these cells enhanced clonal expansion in vitro and formed adenomatous hyperplasia le- sions (the precursor of ADC) in vivo in response to activation of the K-ras gene. They considered that pulmonary ADC originates from these cells.

Ventura et al. [35] produced Cre-mediated recombinant mice in which MAPK14 (p38 ) alleles could be conditionally inactivated with tamoxifen. The most pronounced phenotypic change in mice with a conditionally deleted MAPK14 (p38 $\alpha$ ) gene was lung mal-development, characterized by a prominent increase in cycling peripheral lung epithelial cells, an increase in the number of SP-C positive cells, and a decrease in the number of E-cadherin positive cells. They considered that these phenomena reflect an excess proliferation of peripheral lung stem cells accompanied by an inability to differentiate. It is likely that p38 $\alpha$ helps to prevent the excess proliferation of peripheral lung stem cells and to control pneumocyte differentiation (Fig. 4). They demonstrated that $\mathrm{p} 38 \alpha$ controls the proliferation and selfrenewal of peripheral lung stem cells by mediating such factors as CCAAT/enhancer protein that induce pneumocyte differentiation and inhibit cell replication signals, particularly those of the EGFR signaling pathway. The Clara cell showed no abnormalities. It is interesting that mice with homozygous p38 $\alpha$ gene deletions formed larger and more numerous K-ras gene induced pulmonary tumors than either wild type mice or in mice with heterozygous p38agene deletions. These results indicate that $\mathrm{p} 38 \alpha$ is important not only for control of the self-renewal and differentiation of periph-

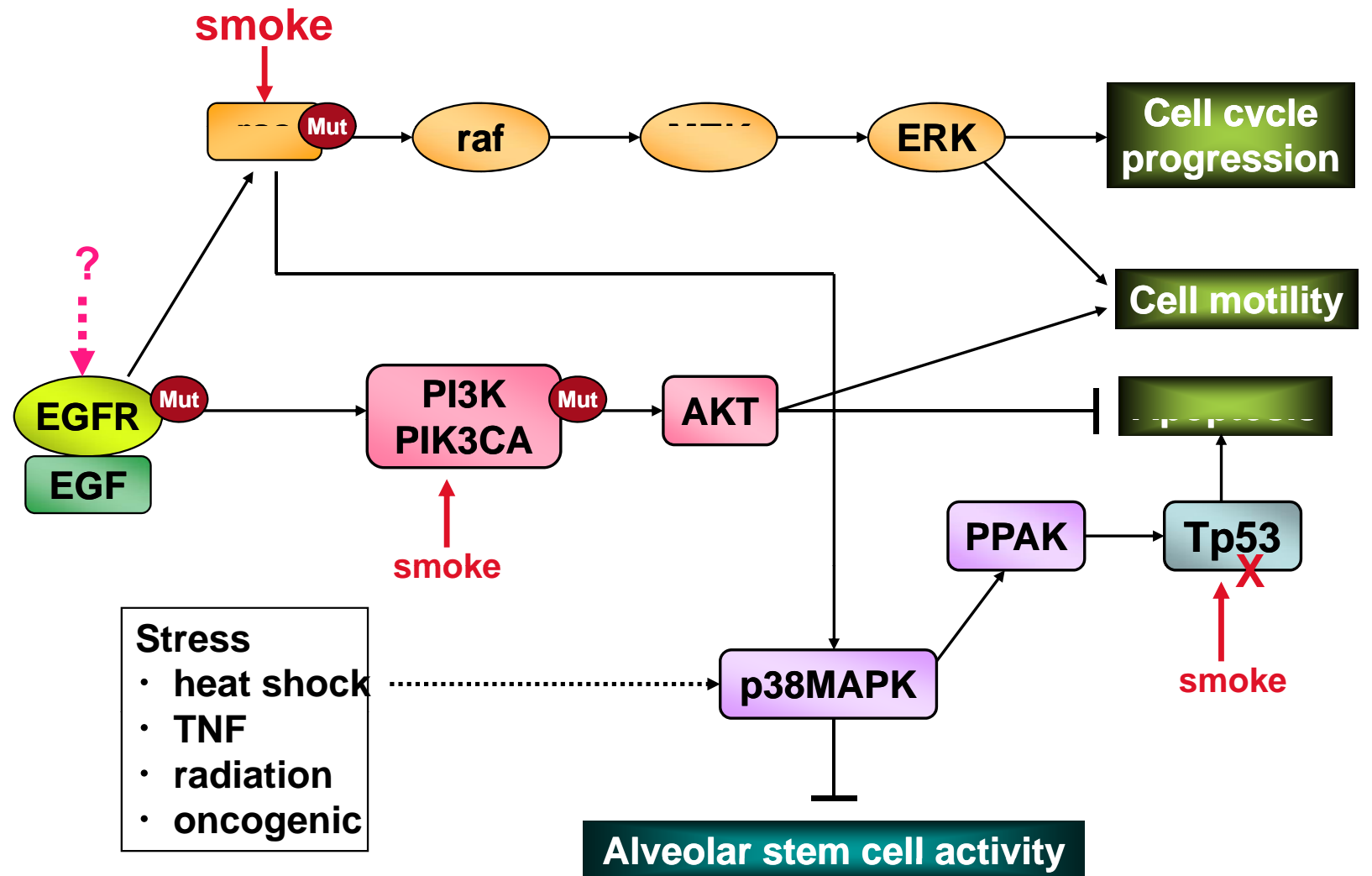

Mut : activating mutations
$\mathrm{X}$ : inactivation

Fig. (4). The role of EGFR signaling pathway involving the ras-raf-MEK-MAPK and PI3K-AKT pathways in coordinating cell cycle progression, cell motility, apoptosis, and alveolar stem cell activity. Activation of EGFR signaling pathway is crucial for carcinogenesis of NSCLC, especially ADC. Smoke carcinogens cause activating mutations of K-ras and PI3K catalytic alpha (PI3KCA) genes, while the etiology of EGFR gene mutations has not been clarified yet. 
eral lung stem cells but also in pulmonary carcinogenesis as a tumor suppressor gene.

In this line, it is of interest that $\mathrm{p} 38$-regulated/activated protein kinase (PRAK), a substrate of p38MAPK, is activated by $\mathrm{p} 38$ in response to the K-ras gene activation in a dimethylbenz[a]-anthracene (DMBA)-induced model of skin carcinogenesis in mice [36]. The activated PRAK induces cell senescence and as a result inhibits the formation of tumors through functional activation of the $\mathrm{Tp} 53$ protein due to direct phosphorylation by this kinase. In addition, $\mathrm{LOH}$ of Dimp1, which is activated through ras-raf signaling and induces cell cycle arrest in a p14/Arf- or Tp53-independent manner, is detected in $35 \%$ of human NSCLC and in $40 \%$ of $\mathrm{K}$-ras gene induced mouse pulmonary ADC, suggesting that Dimp1 is a tumor suppressor [37]. In summary, activation of EGFR signaling pathway is important in the development of $\mathrm{ADC}$ (see below).

In human lung ADC, Tp53 gene inactivation occurs frequently as in other NSCLC, particularly in advanced tumors. On the other hand, $\mathrm{Rb}$ gene inactivation is a rare event. In the study by Ventura et al. [35], the mice with homozygous $\mathrm{Rb}$ gene deletions and normal Tp53 alleles did not develop any ADC. In mice having homozygous deletion of the Tp53 genes, either with normal $\mathrm{Rb}$ genes, heterozygous $\mathrm{Rb}$ gene deletions, or homozygous $\mathrm{Rb}$ gene deletions, lung ADC occurred but there were no differences in incidence among any of the groups. As in human cases, therefore, $\mathrm{Rb}$ gene deletions are not responsible for the development of lung ADC, but Tp53 gene deletions play a crucial role in this mouse model.

\section{Large Cell Carcinoma (LCC)}

LCC is an undifferentiated NSCLC and likely a wastebasket of very poorly differentiated ADC and SCC, and literally undifferentiated carcinomas. It accounts for less than $10 \%$ of all lung cancers. No precursor lesion has been identified yet and the cell of origin is unknown. LCC shares the molecular and genetic alterations seen in other NSCLC [38]. Large cell NE carcinoma (LCNEC) is a unique but still controversial subtype of LCC as it expresses NE markers and partly shares genetic alterations including inactivation of the $\mathrm{Rb}$ and Tp53 genes with SCLC $[38,39]$.

\section{SIGNIFICANCE OF EGFR SIGNALING PATHWAY IN NSCLC}

Activation of the EGFR signaling pathway has a crucial role in NSCLC development [40], in addition to alterations of the p16/INK4-cyclinD1-Rb pathway. A simplified illustration of the EGFR signaling pathway is shown in Fig. (4). As mentioned above, activation of the EGFR gene likely contributes to the development of lung ADC without K-ras gene mutations. Activation of either the K-ras gene or EGFR gene endows cells with the same growth stimuli through the EGFR-ras-raf-MAPK signal transduction cascade. It thus appears that mutations of the K-ras gene and activation of the EGFR gene could work in a complementary manner in the development of lung ADC. Moreover, a downstream component, the PIK3CA gene activation is demonstrated in certain, but rather small proportion of lung ADC. Activation of PIK3CA gene is a significantly frequent event in lung
SCC. In addition, the majority of lung SCC shows overexpression of EGFR, which potentially brings about growth stimulation through the EGFR signaling pathway. Thus, the genes related to EGFR signaling pathway are candidates for targeted therapies, as exemplified by the treatment of lung ADC having EGFR mutations with tyrosine kinase inhibitors $[40,41]$.

\section{EVASION OF FEEDBACK SYSTEM PREVENTING EX- CESSIVE GROWTH BY CARCINOGENIC STRESSES}

As shown in many studies [42-44], the normal cell has a potent to prevent itself from undergoing neoplastic transformation in response to oncogenic stresses. One of the preventive mechanisms is that of so-called tumor suppressor genes, and the most representative one is $\mathrm{Tp} 53$ gene whose product induces cell cycle arrest for repairing DNA damages and eliminates cells with unrecoverable DNA damages by apoptosis [10]. It is thus most likely that disruption of these anticarcinogenic, preventive mechanisms results in neoplastic transformation of the cells, especially when growthpromoting effects by carcinogenic stimuli are accompanied.

We recently showed that mutated K-ras gene transduction in normal epithelial cells derived from the peripheral lung evoked strong expression of insulin-like growth factor (IGF) binding protein-4 and -2 which inhibit cell growth effects of IGF, while many lung carcinoma cell lines expressed these proteins significantly weaker than the normal cells. It was shown that this disruption of IGF binding protein expression in cancer cells was caused by promoter hypermethylation of the IGF binding protein- 4 and -2 genes [45]. This study clearly demonstrated that evasion of the growth-preventive feedback system working in the normal cell is one important mechanism of enhancement of tumor development and that an epigenetic change such as promoter hypermethylation is one of the mechanisms inactivating the genes involved in carcinogenesis.

\section{CONCLUDING REMARKS}

It is undoubtedly rational to divide lung cancers into SCLC and NSCLC, not only from the point of view of clinicopathological characteristics but also with regard to the molecular and genetic pathogenesis.

In SCLC, the Tp53 and $\mathrm{Rb}$ genes are intrinsically and constitutionally inactivated through mutations and/or deletions in virtually all cases, and inactivation of both genes probably is an essential, and presumably early, event. In the vast majority of SCLC, Rb activity should be abraded almost completely due to either loss or constitutional alterations of $\mathrm{Rb}$ protein.

In NSCLC, dysfunction of the Rb pathway ensues from inactivation of multiple upstream regulators, thus repression of $\mathrm{Rb}$ function is assumed not to be complete as in SCLC because putative complementary functions could work through preserved collateral pathways. However, contributions of other $\mathrm{Rb}$ family member pocket proteins, $\mathrm{p} 107$ and p130, should also be kept in mind, since these Rb family proteins show functional redundancy in regulation of proliferation, survival and differentiation of the airway epithelial cells, especially in the NE lineage [27]. With regard to the alterations of the $\mathrm{Tp} 53$ gene, we currently have no information on at which step they occur during the carcinogenesis of 
SCLC. We speculate that Tp53 gene alterations are early events as suggested by the findings in the mouse SCLC model.

On the other hand, activation of the EGFR signaling pathway is a main, and possibly an early event in NSCLC. In ADC, activating mutations of the K-ras gene and EGFR gene are demonstrated in a mutually exclusive fashion as early as in AAH lesions, and advanced ADC lesions as well. In the majority of SCC, EGFR protein is upregulated by a still unknown mechanism. In addition, PIK3CA, a subunit of the intermediate component PI3K of the EGFR signaling pathway, is frequently activated by mutations and amplification in SCC.

It would be right to say that the notion mentioned above is too simplified, as there would be extensive overlap and interaction within the pathways. If correct, however, the next question is what factors are responsible for the differences in molecular carcinogenesis between SCLC and NSCLC. Are etiological factors, the sensitivity of target genes to carcinogenic insults, or the degree of disruption of DNA damage repairing capability different? Are the types of precursor cells targeted by genetic insults different? One plausible theory is that the target precursor cells differ and that the genes functionally important in these cells are sensitive and prone to alteration by carcinogenic insults. In addition, the kinds of carcinogenic insults that induce such alterations could be different and specific for the genes involved depending upon the structure of DNA strands. Tobacco smoke contains over 60 carcinogens such as benzo[a]pyrene, most of which form DNA adducts after metabolic activation in the target cells. The ensuing gene mutational spectra, plausibly involving genes as well, are significantly different depending upon the type of carcinogen. For example, the pattern of Tp53 gene mutations in lung cancers of smokers represents benzo[a]pyrene-induced mutational spectra [8]. In this regard it is interesting that the distribution of frequency of histological types of lung cancer differs significantly between smokers and non-smokers. SCLC and SCC are closely correlated with smoking. ADCs with K-ras mutations are also associated with smoking, while there is little association between smoking and EGFR mutations in ADC, particularly $\mathrm{BAC}$ (Fig. 4). In regard to $\mathrm{Rb}$ gene alterations, what roles smoke does play are not known.

The link of lung cancer development to exogenous carcinogen exposure is strong; however, the difference in susceptibility also has to be considered. The study of genetic polymorphisms relating to xenobiotic metabolism and DNArepair has identified many candidate genes, and it is plausible that some of these genes influence the risk of lung cancer, either by themselves or in combination, as well as lifestyle factors [46].

The phenotypes of cancer cells, for example NE features of SCLC, epidermoid features of SCC, and type 2 pneumocytes and/or Clara cell features of ADC, may be determined by the commitment status of the respective precursor cells. The airway epithelial cell lineage and the molecular mechanism controlling the differentiation and self-renewal of tissue stem cells are still controversial and little understood. Elucidation of the signal transduction pathway and genetic mechanism in the maintenance and activation of lung epithelial stem cells is essential for understanding the molecular pathogenesis of lung cancer. Finally, we would like to stress the importance of epigenetic mechanisms in the functional alterations of genes during carcinogenesis.

\section{ACKNOWLEDGEMENT}

This study was supported in part by Grants from the Smoking Research Foundation of Japan.

\section{ABBREVIATIONS}

$\begin{array}{ll}\mathrm{Bcl}-2 & =\mathrm{B} \text { cell leukaemia/lymphoma-2 } \\ \mathrm{Cdk} & =\text { Cycling dependent kinase } \\ \mathrm{E} 2 \mathrm{~F} & =\mathrm{E} 2 \text { promoter-binding factor } \\ \mathrm{EGFR} & =\text { Epidermal growth factor receptor } \\ \mathrm{MAPK} & =\text { Mitogen-activated protein kinase } \\ \mathrm{Mdm} 2 & =\text { Murine double minute } 2 \\ \mathrm{NE} & =\text { Neuroendocrine } \\ \mathrm{PI} 3 \mathrm{~K} & =\text { Phosphatidylinositol-3-kinase } \\ \mathrm{Rb} & =\text { Retinoblastoma } \\ \mathrm{Tp} 53 & =\text { Tumor protein } 53\end{array}$

\section{REFERENCES}

[1] Parkin M, Tyczynski JE, Boffetta P, Samet J, Shields P, Caporaso N. Lung cancer epidemiology and etiology. In: Travis WD, Brambilla E, Mueller-Hermelink HK, Harris CC, Eds. Tumours of the lung. Tumours of the lung, pleura, thymus and heart. World Health Organization Classification of Tumours. Pathology \& Genetics. Lyon, IARC Press 2004; $12-5$.

[2] Working Group Collaborated with IAP and IASLC. Tumours of the lung. In: Travis WD, Brambilla E, Mueller-Hermelink HK, Harris CC, Eds. Tumours of the lung, pleura, thymus and heart. World Health Organization Classification of Tumours. Pathology \& Genetics. Lyon, IARC Press, 2004, 9-124.

[3] Otto WR. Lung epithelial stem cells. J Pathol 2002; 197: 527-35.

[4] Blanpain C, Horseley V, Fuchs E. Epithelial stem cells: turning over new leaves. Cell 2007; 128: 445-58.

[5] Nuciforo P, Fraggetta F. Cancer stem cell theory: pathologists' considerations and ruminations about wasting time and wrong evaluations. J Clin Pathol 2004; 57: 782-3.

[6] Aldinucci D, Perris R. Cell origin of tumors and the persistence of cancer propagating cells in tumor lesions. Open Pathol J 2008; 2: 612.

[7] Hanahan D, Weinberg RA. The hallmarks of cancer. Cell 2000; 100: 57-70.

[8] Gazdar A, Franklin WA, Brambilla E, Hainaut P, Yokota J, Harris CC. Genetic and molecular alterations. In: Travis WD, Brambilla E, Mueller-Hermelink HK, Harris CC, Eds. Tumours of the lung. Tumours of the lung, pleura, thymus and heart. World Health Organization Classification of Tumours. Pathology \& Genetics. Lyon, IARC Press 2004; 21-33.

[9] $\mathrm{Xu} \mathrm{Y}$. Induction of genetic instability by gain-of-function p53 cancer mutations. Oncogene 2008; 27: 3501-7.

[10] Millau JF, Bastien N, Droun R. P53 transcriptional activities: a general overview and some thought. Mutat Res 2008 Jun 27, doi: 10.1016/j.mrrev.2008.06.002. Available from http://www.science direct.com/science?_ob=ArticleURL\&_udi=B6T2G-4SVKSWV-1 \&_user $=790981 \&$ rdoc $=1 \&$ fmt $=\&$ orig $=$ search $\&$ _sort $=\mathrm{d} \&$ view $=$ 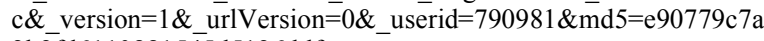 2b2fd6110881545d5126ddf

[11] Kerr KM, Fraire AE, Pugatch B, Vazquez MF, Kitamura H, Niho S. Atypical adenomatous hyperplasia. In: Travis WD, Brambilla E, Mueller-Hermelink HK, Harris CC, Eds. Tumours of the lung. Tumours of the lung, pleura, thymus and heart. World Health Organization Classification of Tumours. Pathology \& Genetics. Lyon, IARC Press 2004; 73-5.

[12] Colby TV, Noguchi M, Henschke C, et al. Adenocarcinoma. In: Travis WD, Brambilla E, Mueller-Hermelink HK, Harris CC, Eds. 
Tumours of the lung. Tumours of the lung, pleura, thymus and heart. World Health Organization Classification of Tumours. Pathology \& Genetics. Lyon, IARC Press 2004; 35-44.

[13] Franklin WA, Wistuba II, Geisinger K, et al. Squamous dysplasia and carcinoma in situ. In: Travis WD, Brambilla E, MuellerHermelink HK, Harris CC, Eds. Tumours of the lung. Tumours of the lung, pleura, thymus and heart. World Health Organization Classification of Tumours. Pathology \& Genetics. Lyon, IARC Press 2004; 68-72.

[14] Meuwissen R, Linn SC, Linnoila RI, Zevenhoven J, Mooi WJ, Berns A. Induction of small cell lung cancer by somatic inactivation of both $\operatorname{Trp} 53$ and $R b 1$ in a conditional mouse model. Cancer Cell 2003; 4: 16-25.

[15] Kaye FJ. RB and cyclin dependent kinase pathways: defining a distinction between RB and p16 loss in lung cancer. Oncogene 2002; 21: 6908-14.

[16] Wikman H, Kettunen E. Regulation of the G1/S phase of the cell cycle and alterations in the RB pathway in human lung cancer. Expert Rev Anticancer Ther 2006; 6: 515-30.

[17] Hammar SP, Brambilla C, Pugatch B, et al. Squamous cell carcinoma. In: Travis WD, Brambilla E, Mueller-Hermelink HK, Harris $\mathrm{CC}$, Eds. Tumours of the lung. Tumours of the lung, pleura, thymus and heart. World Health Organization Classification of Tumours. Pathology \& Genetics. Lyon, IARC Press 2004; 26-30.

[18] Brambilla E, Moro D, Gazzeri S, Brambilla C. Alterations of expression of $\mathrm{Rb}, \mathrm{p} 14^{\mathrm{INK} 4 \mathrm{~A}}$ and cyclin D1 in non-small cell lung carcinoma and their clinical significance. J Pathol 1999; 188: 351-60.

[19] Harbour JW, Dean DC. The Rb/E2F pathway: expanding roles and emerging paradigms. Genes Dev 2000; 14: 2393-2409.

[20] Iaquinta PJ, Lees JA. Life and death decisions by the E2F transcription factors. Curr Opin Cell Biol 2007; 19: 649-57.

[21] Travis W, Nicholson S, Hirsch FR, et al. Small cell carcinoma. In: Travis WD, Brambilla E, Mueller-Hermelink HK, Harris CC, Eds. Tumours of the lung. Tumours of the lung, pleura, thymus and heart. World Health Organization Classification of Tumours. Pathology \& Genetics. Lyon, IARC Press 2004; 31-4.

[22] Eymin B, Gazzeri S, Brambilla C, Brambilla E. Distinct pattern of E2F1 expression in human lung tumours: E2F1 is upregulated in small cell lung carcinoma. Oncogene 2001; 20: 1678-87.

[23] Cooper CS, Nicholson AG, Foste C, et al. Nuclear overexpression of the E2F3 transcription factor in human lung cancer. Lung Cancer 2006; 54: 155-62.

[24] Johnson BE, Russell E, Simmons AM, et al. Myc family DNA amplification in 126 tumor cell lines from patients with small cell lung cancer. J Cell Biochem 1996; (Suppl)24: 210-7.

[25] Kim YH, Girard L, Giacomini CP, et al. Combined microarray analysis of small cell lung cancer reveals altered apoptotic balance and distinct expression signatures of Myc-family gene amplification. Oncogene 2006; 25: 130-8.

[26] Wang DG, Johnston CF, Sloan JM, Buchanan KD. Expression of $\mathrm{Bcl}-2$ in lung neuroendocrine tumours: comparison with $\mathrm{p} 53$. J Pathol 1998; 184: 247-51.

[27] Wikenheiser-Brokamp KA. Rb family proteins differentially regulate distinct cell lineages during epithelial development. Development 2004; 131: 4299-4319.

[28] Suzuki M, Shigematsu H, Hiroshima K, et al. Epidermal growth factor receptor expression status in lung cancer correlates with its mutation. Hum Pathol 2005; 36: 1127-34.

[29] Okudela K, Suzuki M, Kageyama S, et al. PIK3CA mutation and amplification in human lung cancer. Pathol Int 2007; 57: 664-71.

[30] Kitamura H, Kameda Y, Ito T, Hayashi H. Atypical adenomatous hyperplasia of the lung. Implications for the pathogenesis of peripheral lung adenocarcinoma. Am J Clin Pathol 1999; 111: 61022.
[31] Yoshida Y, Shibata T, Kokubo A, et al. Mutations of the epidermal growth factor receptor gene in atypical adenomatous hyperplasia and bronchioloalveolar carcinoma of the lung. Lung Cancer 2005; 50: $1-8$.

[32] Suzuki M, Shigematsu H, Iizasa T, et al. Exclusive mutation in epidermal growth factor receptor gene, HER-2, and K-RAS, and synchronous methylation of nonsmall cell lung cancer. Cancer 2006; 106: 2200-7.

[33] Sakamoto H, Shimizu J, Horio Y, et al. Disproportionate representation of $K R A S$ gene mutation in atypical adenomatous hyperplasia, but even distribution of $E G F R$ gene mutation from preinvasive to invasive adenocarcinomas. J Pathol 2007; 212: 287-94.

[34] Kim CB, Jackson EL, Woolfenden AE, et al. Identification of bronchioloalveolar stem cells in normal lung and lung cancer. Cell 2005; 121: 85-97.

[35] Ventura JJ, Tenbaum S, Perdiquero E, et al. p38 MAP kinase is essential in lung stem and progenitor cell proliferation and differentiation. Nat Genet 2007; 39: 750-8.

[36] Sun P, Yoshizuka N, New L, et al. PRAK is essential for rasinduced senescence and tumor suppression. Cell 2007; 128: 295308.

[37] Mallakin A, Sugiyama T, Taneja P, et al. Mutually exclusive inactivation of DMP1 and ARF/p53 in lung cancer. Cancer Cell 2007; 12: 381-94.

[38] Brambilla E, Pugatch B, Geisinger K, et al. Large cell carcinoma In: Travis WD, Brambilla E, Mueller-Hermelink HK, Harris CC, Eds. Tumours of the lung. Tumours of the lung, pleura, thymus and heart. World Health Organization Classification of Tumours. Pathology \& Genetics. Lyon, IARC Press 2004; 45-50.

[39] Travis WD. The concept of pulmonary neuroendocrine tumours. In: Travis WD, Brambilla E, Mueller-Hermelink HK, Harris CC, Eds. Tumours of the lung. Tumours of the lung, pleura, thymus and heart. World Health Organization Classification of Tumours. Pathology \& Genetics. Lyon, IARC Press 2004; 19-20.

[40] Shigematsu H, Gazdar AF. Somatic mutations of epidermal growth factor receptor signaling pathway in lung cancers. Int $\mathrm{J}$ Cancer 2006; 118: 257-62.

[41] Yun C-H, Boggon TJ, Li Y, et al. Structures of lung cancer-derived EGFR mutants and inhibitor complexes: mechanism of activation and insights into differential inhibitor sensitivity. Cancer Cell 2007; 11: 217-27.

[42] Ben-Porath I, Weinberg RA. The signals and pathways activating cellular senescence. Int J Biochem 2005; 37: 961-76.

[43] Cheung CTY, Hasan MK, Widodo N, Kaul SC, Wadhwa R. CRF: An emerging regulator of p53 tumor suppressor and senescence pathway. Mech Ageing Dev 2008 May 8, doi: 10.1016/j.mad.2008. 05.002. Available from: http://www.sciencedirect.com/science? ob=ArticleURL\&_udi=B6T31-4SFXK4B-1\&_user=790981\&_rdo 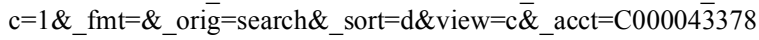 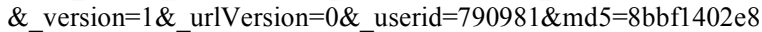 $411 \mathrm{c} 0 \mathrm{ce} 11 \mathrm{~d} 39$ ea $1 \mathrm{a} 8 \mathrm{fc} 918$

[44] Fridman AL, Tainsky MA. Critical pathways in cellular senescence and immortalization revealed by gene expression profiling. Oncogene 2008 Aug 18, doi: 10.1038/onc.2008.213. Available from: http://www.nature.com/onc/journal/vaop/ncurrent/abs/onc2008213 a.html

[45] Sato H, Yazawa T, Suzuki T, et al. Growth regulation via insulinlike growth factor binding protein-4 and -2 in association with mutant K-ras in lung epithelia. Am J Pathol 2006; 169: 1550-66.

[46] Bartsch H, Haugen A, Risch A, Shields P, Vineis P. Genetic susceptibility. In: Travis WD, Brambilla E, Mueller-Hermelink HK, Harris CC, Ed. Tumours of the lung. Tumours of the lung, pleura, thymus and heart. World Health Organization Classification of Tumours. Pathology \& Genetics. Lyon, IARC Press 2004; 24-5. 